\title{
Pulmonary Artery Aneurysm Causing Left Main Coronary Artery Disease
}

\section{(1) Baburhan Özbek1, (1) Nursen Tanrıkulu2}

1Van Training and Research Hospital, Clinic of Pediatric Cardiovascular Surgery, Van, Turkey

${ }^{2}$ Kolan International Hospital, Clinic of Anesthesiology, İstanbul, Turkey

\begin{abstract}
Pulmonary artery aneurysm is a rare clinical condition but may lead to serious complications such as pulmonary artery dissection, rupture and compression of left main coronary artery. The relation between the pulmonary artery and the adjacent structures should be considered after the diagnosis of the aneurysm. Surgery is suggested in the patients with increased diameter of the pulmonary artery or symptoms caused by the compression to the neighborhood tissues. In this case, we are reporting a 52-year-old female patient with
\end{abstract}

\section{Introduction}

Pulmonary artery aneurysm (PAA) is a rare clinical condition, which might be developed congenitally or acquired $^{(1)}$. Main pulmonary artery diameter over 43.4 $\mathrm{mm}$ in males and $40.4 \mathrm{~mm}$ in females or 1.5 times wider than normal values is defined as $\mathrm{PAA}^{(2)}$. Congenital cardiac diseases, connective tissue diseases, vasculitis, pulmonary artery aneurysm causing the compression of left main coronary artery and presenting with chest pain. Owing to the successful surgical correction of the aneurysm, the compression of the left main coronary artery was removed. Relief of the coronary artery from the compression might be enough to improve symptoms in the patients with pulmonary artery aneurysm.

Keywords: Aneurysm, dissection, left main coronary artery, pulmonary artery

endocarditis, infection, pulmonary hypertension, neoplasia, trauma, pulmonary cardiac disease, pulmonary artery dissection, pulmonary embolism, arteriovenous fistula and idiopathic causes were reported in the etiology of the PAA ${ }^{(3)}$.

PAA has no specific symptoms. PAA might cause compression on neighboring structures by getting

Address for Correspondence: Baburhan Özbek, Van Training and Research Hospital, Clinic of Pediatric Cardiovascular Surgery, Van, Turkey

Phone: +90 5055916057 e-mail: baburhanozbek@gmail.com ORCID ID: orcid.org/0000-0002-3671-2128

Received: 10.02.2019 Accepted: 22.05.2019

Cite this article as: Özbek B, Tanrıkulu N. Pulmonary Artery Aneurysm Causing Left Main Coronary Artery Disease. EJCM 2019;7(2):98-100.

DOI: $10.32596 /$ ejcm.2019.00006

${ }^{\circ}$ Copyright 2019 by Heart and Health Foundation of Turkey (TÜSAV) / E Journal of Cardiovascular Medicine published by Galenos Publishing House. 
wider and patients might be symptomatic due to the compression $^{(4)}$. Cough, dyspnea, hoarseness, pulmonary artery fistulization to trachea, hemoptysis and chest pain might develop according to the compressed tissue. In this case we are presenting successful surgical treatment of PAA that referred with chest pain and dyspnea.

\section{Case Report}

A 52-year-old patient referred to our clinic with the complaints of chest pain and dyspnea. The functional capacity of the patient was New York Heart Association (NYHA) class 3 and vital findings were normal. In the chest radiography, cardiothoracic ratio had minimally increased (0.55) and pulmonary artery shadow was pronounced. Pulmonary artery was enlarged with the diameter of 54 $\mathrm{mm}$. in the transthoracic echocardiography (TTE). Also, there were $12 \mathrm{~mm}$. secundum type atrial septal defect, mild tricuspid and pulmonary valve regurgitation. Left main coronary artery (LMCA) disease caused by the compression of the PAA was diagnosed in the coronary angiography (Figure 1). Mean pulmonary artery pressure was $32 \mathrm{mmHg}$. Computed tomography revealed main PAA with the diameter of $56 \mathrm{~mm}$. That extending to the

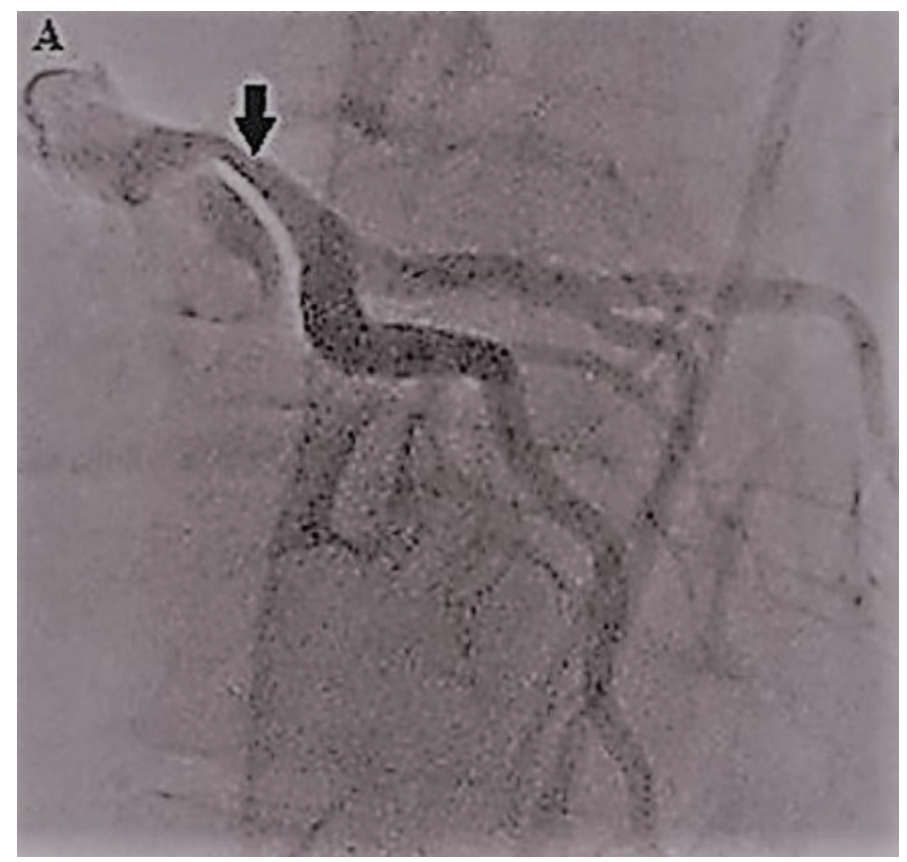

Figure 1A. Left main coronary artery stenosis due to compression of the pulmonary artery aneurysm right and left pulmonary arterial branches and compressed on LMCA.

After the median sternotomy and pericardiotomy expansion in pulmonary artery and its branches was noted. Standard cardiopulmonary bypass (CPB) was maintained with aortic and bicaval venous cannulation. Aneurysmatic pulmonary artery was exposed. Pulmonary arteriotomy was done. Pulmonary valve had a normal anatomic structure, then aneurysmatic pulmonary artery was extracted. Graft interposition of $32 \mathrm{~mm}$ Dacron graft for the main pulmonary artery and $28 \mathrm{~mm}$ Dacron graft for pulmonary arterial branches was done with 4-0 prolene stitches. Atrial septal defect was repaired with pericardial patch. Operation was ended after termination of the CPB. Aortic cross clamp time was 111 minutes and total perfusion time was 136 minutes. The patient was extubated on postoperative seventh hour. There was mild tricuspid valve regurgitation and low pulmonary arterial hypertension in the postoperative second day control TTE. Control angiography was performed at postoperative $5^{\text {th }}$ day and it was observed that the stenosis caused by the external compression on LMCA had completely disappeared (Figure 2). The patient was discharged from the hospital on postoperative seventh day. Postoperative functional capacity of the patient was observed as NYHA class 1 in follow-up period.

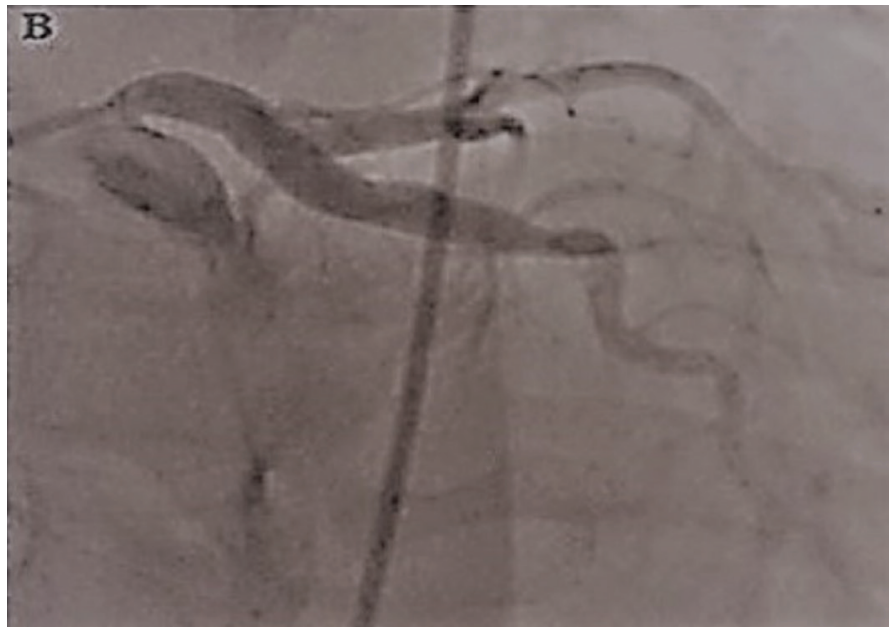

Figure 1B. View of the left main coronary artery after removal of the compression 
Informed consent form was obtained from the patient.

\section{Discussion}

PAA involving main pulmonary artery together with its branches are rare as in our case and it was reported with rate of $11 \%$ of all PAAs ${ }^{(5)}$. External compression of the coronary arteries might be presented as coronary arterial disease. In this clinic condition relief of compression might be enough for the treatment rather than the coronary artery bypass grafting. In our case we diagnosed external compression of the PAA to the LMCA in the detailed examination. There is no need to coronary artery bypass grafting after decompression of the PAA.

Although there is no exact mechanism of the etiology, cystic medial degeneration of the media layer of pulmonary artery or prostaglandin E receptors might play role for the development of the PAA ${ }^{(6)}$. In the surgical indication of the PAA, there is not any consensus yet. However, pulmonary arterial dissection of PAA with the diameter of $60 \times 55$ $\mathrm{mm}$ was reported in the literature ${ }^{(7)}$. Compression to the LMCA, higher than $55 \mathrm{~mm}$ pulmonary artery diameter is suggested for surgical intervention ${ }^{(8)}$.

Different techniques such as pericardial patchplasty, aneurysmorrhaphy, plication and graft interposition are among surgical strategies ${ }^{(9)}$. Plication is a fast and easy technique to apply, but recurrence might develop after this surgical procedure. Graft interposition decreases the recurrence risk with the advantages of extraction of the native vessel wall ${ }^{(10)}$. In our patient we performed graft interposition to the main pulmonary artery and its branches. There was not any complication in the perioperative period and postoperative follow-up.

PAA might be kept in mind in the differential diagnosis of the non-specific complaints such as dyspnea, chest pain, cough and hoarseness. In the patients with compressed coronary arteries it might presented as coronary artery disease. Surgical treatment of the PAA might be enough in the complications caused by the compression syndrome.

\section{Ethics}

Informed Consent: Informed consent form was obtained from the patient.

Peer-review: Externally and internally peer-reviewed.

\section{Authorship Contributions}

Surgical and Medical Practices: B.Ö., N.T., Concept: B.Ö., Design: B.Ö., Data Collection or Processing: B.Ö., Analysis or Interpretation: B.Ö., N.T., Literature Search: N.T., Writing: B.Ö., N.T.

Conflict of Interest: No conflict of interest was declared by the authors.

Financial Disclosure: The authors declared that this study received no financial support.

\section{References}

1. Tsui EYK, Chung YK, Chow L, Chau LF, Yu SK, Chan JHM. Idiopathic pulmonary artery aneurysm: digital subtraction pulmonary angiography grossly underestimates the size of the aneurysm. J Clin Imaging 2001;25:178-80

2. Shankarappa RK, Moorthy N, Chandrasekaran D, Nanjappa MC. Giant Pulmonary Artery Aneurysm Secondary to Primary Pulmonary Hypertension. Tex Heart Inst J 2017;37:244-5.

3. Kreibich M, Siepe M, Kroll J, Hohn R, Grohmann J. Aneurysms of the pulmonary artery. Circulation 2015;131:310-6.

4. Nair KKS, Cobanoglu AM. Idiopathic main pulmonary artery aneurysm. Ann Thorac Surg 2001;71:1688-90.

5. Cipollone F, Fazia ML, Lezzi A, et al. Association between prostaglandin E receptor subtype EP4 overexpression and unstable phenotype in atherosclerotic plaques in human. Arterioscler Thromb Vasc Biol 2005;25:1925-31.

6. Lopez-Candales A, Kleiger RE, Aleman-Gomez J, Kouchoukos NT, Botney MD. Pulmonary artery aneurysm: Review and case report. Clin Cardiol $1995 ; 18: 738-40$

7. Hamawy AH, Cartledge RG, Girardi LN. Graft repair of a pulmonary artery aneurysm. Heart Surg Forum 2002;5:396-8.

8. Zylkowska J, Kurzyna M, Florczyk M, et al. Pulmonary artery dilatation correlates with the risk of unexpected death in chronic arterial or thromboembolic pulmonary hypertansion. Chest 2012;142:1406-16.

9. Kuwaki K, Morishita K, Sato H, Urita R, Abe T. Surgical repair of the pulmonary trunk aneurysm. Eur J Cardiothorac Surg 2000;18:535-9.

10. Garcia A, Byrne JG, Bueno R, Flores RM. Aneurysm of the main pulmonary artery. Ann Thorac Cardiovasc Surg 2008;14:399-401. 